\title{
Associations between Physical Functioning and Psychosocial Factors in Patients with Type-2 Diabetes Mellitus
}

\author{
Christy B Adeyege ${ }^{1}$, Taofeek O Awotidebe ${ }^{2 *}$, Olufesola M Fasakin ${ }^{3}$, Taofiq O Afolabi ${ }^{4}$, \\ Rufus A Adedoyin ${ }^{2}$ and Babatope A Kolawole ${ }^{5,6}$
}

${ }^{1}$ Department of Medical Rehabilitation, Obafemi Awolowo University Teaching Hospitals Complex, Nigeria ${ }^{2}$ Department of Medical Rehabilitation, College of Health Sciences, Obafemi Awolowo University, Ile-Ife, Nigeria

${ }^{3}$ Nursing Services Department, Veterans Affairs Medical Center, Dallas, USA

${ }^{4}$ Physiotherapy Department, University of Medical Sciences, Ondo State, Nigeria

${ }^{5}$ Department of Medicine, College of Health Sciences, Obafemi Awolowo University, Ile-Ife, Nigeria

${ }^{6}$ Endocrinology and Metabolism Unit, Obafemi Awolowo University Teaching Hospitals Complex, Ile-Ife, Nigeria

*Corresponding author: Taofeek O Awotidebe, PT, PhD, Department of Medical Rehabilitation, College of Health Sciences, Obafemi Awolowo University, Ile-Ife, Nigeria, Tel: +2348037196021; +2348188981415

\section{Abstract}

Background: Type-2 Diabetes Mellitus (T2DM) could impact on both physical performance and psychological well-being. However, the link between physical functioning $(\mathrm{PhF})$ and psychosocial factors (PsF) of patients with T2DM remains unclear. This study investigated the associations between PhF and PsF in patients with T2DM.

Methods: This cross-sectional study involved 140 patients with T2DM receiving treatment at a Nigerian tertiary hospital using purposive sampling technique. Socio-demographic data were recorded. PhF including Activity of Daily Living (ADL), Hand Grip Strength (HGS) and functional capacity (FC) were assessed using the Multidimensional Health Assessment Questionnaire, hand dynamometer and 6-Minute Walk Test respectively. PsF including depressive symptoms (DpS), exercise self-efficacy (ESE) and perceived exercise benefit (PEB) were assessed using the Center for Epidemiology Studies Depression Scale, ESE and PEB Scales respectively. Descriptive and inferential statistics were used to analyze data. Alpha level was set at $p<0.05$.

Results: The mean age of participants was $61.53 \pm 12.23$ years. Participants were comparable in all physical characteristics, clinical variables, PhF and PsF except in height, body weight, HGS, and 6-Minute Walk Distance (6-MWD) $(p<0.05)$. Less than a fifth, $21(15.0 \%)$ exhibited DpS with married and widow participants almost twice likely to suffer depression; OR $=1.87(95 \% \mathrm{Cl}=0.40-8.76 ; \mathrm{p}=0.027)$ and $\mathrm{OR}=1.65(95 \% \mathrm{Cl}=0.54-6.33 ; p=0.034)$ respectively. There was no significant association between PhF and depression. However, there were significant associations
\end{abstract}

between high ESE and each of PhF (ADL: OR $=2.20$, $95 \% \mathrm{Cl}=1.12-4.14 ; \mathrm{p}=0.026)$, $(\mathrm{HGS}: \mathrm{OR}=2.85,95 \% \mathrm{Cl}$ $=2.58-3.12 ; \mathrm{p}=0.012)$ and $(6-\mathrm{MWD}: \mathrm{OR}=2.96,95 \% \mathrm{Cl}=$ $1.91-4.58 ; p=0.003)$. Similarly, there were significant associations between high PEB and each of PhF (ADL: OR $=2.41,95 \% \mathrm{Cl}=1.27-4.57 ; \mathrm{p}=0.017$ ), (HGS: OR = 1.84; $95 \% \mathrm{Cl}=1.09-3.12 ; \mathrm{p}=0.039)$ and (6-MWD: $\mathrm{OR}=3.34$, $95 \% \mathrm{Cl}=1.08-10.27 ; \mathrm{p}=0.034)$.

Conclusion: Patients with T2DM exhibited reduced PhF in terms of ADL, HGS and 6-MWD but demonstrated moderate to high ESE and PEB. However, a sizable number of patients with T2DM presented with some level of depression. Furthermore, PhF was significantly associated with high ESE and PEB. Improved PhF and better PsF could enhance rehabilitation outcomes in people with T2DM.

\section{Keywords}

Depression, Physical function, Psycho-social factor, Type-2 diabetes mellitus
Abbreviations
PhF: Physical functioning; PsF: Psychosocial factor; T2DM: Type-2 Diabetes Mellitus; ADL: Activity of Daily Living; HGS: Hand Grip Strength; FC: Functional capacity; 6-MWT: 6-Minute Walk Test; MDHAQ: Multi-Dimensional Health As- sessment Questionnaire; CES-D: Center for Epidemiologic Studies Depression Scale; DpS: Depressive symptoms; ESE: Exercise self-efficacy; PEB: Perceived exercise bene- fit; SCT: Social Cognitive Theory; OAUTHC: Obafemi Awo- lowo University Teaching Hospitals Complex

Citation: Adeyege CB, Awotidebe TO, Fasakin OM, Afolabi TO, Adedoyin RA, et al. (2021) Associations between Physical Functioning and Psychosocial Factors in Patients with Type-2 Diabetes Mellitus. Int J Diabetes Clin Res 8:136. doi.org/10.23937/2377-3634/1410136

Accepted: March 29, 2021: Published: March 31, 2021

Copyright: (C) 2021 Adeyege CB, et al. This is an open-access article distributed under the terms of the Creative Commons Attribution License, which permits unrestricted use, distribution, and reproduction in any medium, provided the original author and source are credited. 


\section{Introduction}

Diabetes Mellitus (DM) especially Type-2 Diabetes Mellitus (T2DM) is a major and largest growing health emergencies of the $21^{\text {st }}$ century for which no age group is spared owing to changes in lifestyle worldwide [1]. Currently, more than 171 million people worldwide is affected and the number is expected to rise to $366 \mathrm{mil}-$ lion by 2030 [2]. It is now largely believed that T2DM is almost reaching epidemic proportions with sub-Sahara Africa region having the highest prevalence [3].

In sub-Sahara Africa, the actual prevalence of T2DM is not known but findings from the region showed that a prevalence of about $13.1 \%$ was estimated. For example, it was estimated that Tanzania urban/rural ratio is $5: 1$ while Cameroon has a ratio of 2:1 [4]. Again, it was estimated that undiagnosed T2DM accounts for $60 \%$ of those with the disease in Cameroon, 70\% in Ghana and over $80 \%$ in Tanzania [5]. Undoubtedly, Nigeria has been reported to have the highest number of people with T2DM having approximately $1,218,000$ people in the country [6]. In addition, the highest number of people with impaired glucose tolerance was estimated to be around 3.85 million people in Nigeria [4].

Type-2 Diabetes Mellitus may present with characteristic symptoms such as hyperglycemia, persistent thirst, polyuria, blurring of vision and weight loss [7]. Persistent hyperglycemia is known to reduce muscular strength, poor exercise tolerance, impairs nerve activity leading to neuropathy, and subsequently resulting to poor physical functioning [8]. Similarly, owing to progressive disabling of T2DM, it may negatively impact on the health-related quality of life due to psychological feeling of being chronically ill, unpalatable dietary restrictions, episodes of hyperglycaemia, unexpected hypoglycaemia, and fear of long term consequences of ill-health [9]. In actual fact, it is a lifelong disability which may increase risk of deconditioning, reduced functional capacity, poor self-esteem and rapid deterioration of health status. Consequently, there could be progressive psychological disturbances that may lead to depression.

Anderson, et al. [10], reported in a study that about $15-30 \%$ of all adults with T2DM had depression with women being twice more likely affected as men. Furthermore, individuals with T2DM were reported to be more likely to exhibit depression, a higher prevalence of low quality of life [11], and increased mortality compared to patients without depression [12]. While the pathway connecting depression and worse outcomes in physical performance in persons with T2DM is yet to be fully elucidated, it is likely to include both physiologic and behavioural factors [13]. Hence, understanding the connections between physical performance and behavioural factors may help to institute strategic and specific rehabilitation regimens for people with T2DM.

In the recent time, studies have shown that treat- ment of diseases such as T2DM could be approached by using the bio-psychosocial model of health for achieving effective rehabilitation goal [14]. The model considers the role of biological, psychological and social factors as part of rehabilitation regimen. Similarly, the Social Cognitive Theory (SCT), a theory that identifies multiple, interacting determinants of human behaviour and behaviour change recognizes perceived benefit and self-regulatory task; self-efficacy as important psychosocial factor in rehabilitation [15]. However, the associations between physical functioning and psychosocial factors of persons with T2DM remain poorly understood.

\section{Objective}

The objective of this study was to investigate the associations between physical functioning and psychosocial factors among persons with T2DM attending a university teaching hospital in southwestern Nigeria.

\section{Materials and Methods}

\section{Study subjects and research design}

Participants for this study were patients with Type2 Diabetes Mellitus (T2DM) receiving treatment at the Endocrinology and Metabolism Unit of the Consultant Out-Patient Department of the Obafemi Awolowo University Teaching Hospitals Complex (OAUTHC), Ile-Ife, Osun State, Nigeria. This study utilized a cross-sectional study design using purposive sampling technique to recruit participants. The eligibility for inclusion were participants whose ages ranged between 25 years and older with clinical diagnosis of T2DM. However, participants with poorly controlled hyperglycemia, previous diagnosis of significant dementia, psychosis, foot ulcer or any musculoskeletal disorders that may limit walking capability were excluded from the study.

The sample size for this study was determined using a sample size formula for cross-sectional study design; $\mathrm{N}=\mathrm{Z}^{2} \mathrm{p}(1-\mathrm{p}) / \mathrm{e}^{2}$, where; $\mathrm{N}=$ required sample size, $\mathrm{Z}=$ $z$-value ( $z$-value at $95 \%$ confidence level $=1.96$ ), $p=$ the estimated proportion of an attribute that is present in the population and $\mathrm{e}=$ the desired level of precision (i.e. confidence interval, expressed as decimal (0.05) [16]. Considering the prevalence $(p)$ of T2DM in Nigerian population to be $10 \%$ [6], a minimum sample size of 125 was estimated for this study. However, an additional $10 \%$ was added to the estimated sample size resulting to approximately 140 participants to accommodate for possible missing data. Ethical clearance for this study was obtained from the Ethics and Research Committee of the OAUTHC (ERC/2018/10/11), Ile - Ife, Osun State, Nigeria. The purpose of the study was explained in detail to the participants. Furthermore, written informed consent was obtained from participants who met the inclusion criteria before the commencement of the study. Information on socio-demographic characteristics including age, gender, marital status occupational, 
monthly income and educational level were recorded. Anthropometric characteristics including body weight, height, hip and waist circumferences were recorded using standard procedures. Data on physical functioning including activity of daily living (ADL), handgrip strength (HGS) and functional capacity (FC) were assessed using the Multi-Dimensional Health Assessment Questionnaire (MDHAQ), hand dynamometer and 6-minute walk test respectively. Participants' fasting blood glucose (FBG) measurements were taken from 7:00 am to 9:00 am in the morning using a portable glucometer (One Touch Lifescan; Johnson-Johnson Company Product, Inc., Milpitas, CA 95035). Psychosocial factors including depressive symptoms was assessed using the Center for Epidemiologic Studies Depression (CES-D) Scale while exercise self-efficacy and perceived exercise benefits were assessed using the exercise self-efficacy scale and perceived exercise benefits and barrier scale respectively.

\section{Assessment of physical functioning}

Activity of daily living (ADL): Activity of Daily Living was assessed using the Multi-Dimensional Health Assessment Questionnaire (MDHAQ). The MDHAQ consists of 10 questions measuring $A D L$ over the last week which ranges from "without any difficulty" $=0$, "with some difficulty" = 1 "with much difficulty" = 2 and "unable to $\mathrm{do}^{\prime \prime}=3$. The instrument has a test-retest reliability of 0.89 using Cronbach alpha [17]. The procedure for the assessment of physical functioning was described in our previous study [18].

Hands grip strength (HGS): The hand grip strength (HGS) of participant was assessed using an electronic hand dynamometer. The procedure for assessing HGS was carried out using the American Society of Hand Therapists guidelines [19]. A demonstration was carried out before handing over the instrument to the participant. The procedure for measuring HGS was described in our previous study [20].

Functional capacity (FC): FC of the participants was assessed using the 6-Minute Walk Test (6-MWT). Based on the American Thoracic Association [21] guidelines, the 6-MWT was performed within the Physiotherapy Unit, Department of Medical Rehabilitation of OAUTHC. A 20 meter level corridor course was marked to perform a 6-MWT. Participant was allowed to rest for a period of 10 minutes in sitting position before the commencement of the walk test. The procedure was for performing the 6-MWT was described in our previous study [22].

\section{Assessment of psychosocial factors}

The following psychosocial factors including depressive symptoms, exercise self-efficacy and perceived exercise benefit were assessed.

Depressive symptoms (DpS): Depressive symptom of participant was assessed using the Center for Epidemiologic Studies Depression (CES-D) Scale. The scale is a well-validated, 10-item; self-report instrument designed to measure depressive symptoms in the general population [23]. With a range from 0 to 3 , any score equals to or above 10 is considered depressed [24].

Exercise self-efficacy (ESE): The Exercise Self-Efficacy Scale developed by Bandura was used to assess the exercise self-efficacy (ESE) of the participants. The scale is a self-administered questionnaire used as measure of the confidence in one's ability to endure with exercise in various situations which represents the areas of negative affect, resisting relapse, and making time for

Table 1: Socio-demographic characteristics and distribution of psychosocial factors of participants $(\mathrm{N}=140)$.

\begin{tabular}{|c|c|c|}
\hline Variable & Frequency & Percentage \\
\hline \multicolumn{3}{|l|}{ Sex } \\
\hline Male & 64 & 45.7 \\
\hline Female & 76 & 54.3 \\
\hline \multicolumn{3}{|l|}{ Marital status } \\
\hline Single & 5 & 3.6 \\
\hline Married & 123 & 87.9 \\
\hline Widow/Widower & 12 & 8.6 \\
\hline \multicolumn{3}{|l|}{ Occupation } \\
\hline Farming & 8 & 5.7 \\
\hline Civil Servant & 24 & 17.1 \\
\hline Trader/Artisan & 61 & 43.6 \\
\hline Retiree & 44 & 31.4 \\
\hline Schooling & 3 & 2.1 \\
\hline \multicolumn{3}{|l|}{ Educational level } \\
\hline Primary & 20 & 14.3 \\
\hline Secondary & 58 & 41.4 \\
\hline Post-Secondary & 62 & 44.3 \\
\hline \multicolumn{3}{|l|}{ DpS } \\
\hline Not depressed & 119 & 85.0 \\
\hline Depressed & 21 & 15.0 \\
\hline \multicolumn{3}{|l|}{ ESE } \\
\hline Low & 60 & 42.9 \\
\hline Moderate & 40 & 28.6 \\
\hline High & 40 & 28.6 \\
\hline \multicolumn{3}{|l|}{ PEB } \\
\hline Low & 30 & 21.4 \\
\hline Moderate & 60 & 42.9 \\
\hline High & 50 & 35.7 \\
\hline \multicolumn{3}{|c|}{ Anti-diabetic medication $^{\dagger}$} \\
\hline Metformin & 85 & 60.7 \\
\hline Diabinese & 55 & 39.3 \\
\hline Miglitol & 35 & 25.0 \\
\hline Liraglutide & 28 & 20.0 \\
\hline
\end{tabular}

Key: DpS: Depressed symptoms; ESE: Exercise self-efficacy; PEB: Perceived exercise benefit; ${ }^{\dagger}$ : Summation greater than $100 \%$ due to combinations of medications. 
Table 2: Comparison of physical, clinical characteristics, physical functioning and psychosocial factors between male and female participants $(\mathrm{N}=140)$.

\begin{tabular}{|c|c|c|c|c|c|}
\hline & All & Male $(n=64)$ & Female $(n=76)$ & & \\
\hline Variable & Mean \pm S.D & Mean \pm S.D & Mean \pm S.D & t-cal. & P-value \\
\hline \multicolumn{6}{|c|}{ Physical characteristics } \\
\hline Age (years) & $61.53 \pm 12.23$ & $63.53 \pm 10.85$ & $59.84 \pm 13.12$ & 1.792 & 0.075 \\
\hline Height (m) & $1.63 \pm 0.08$ & $1.67 \pm 0.08$ & $1.59 \pm 0.06$ & 6.161 & $0.001^{*}$ \\
\hline Weight (kg) & $72.09 \pm 12.12$ & $74.51 \pm 11.39$ & $70.06 \pm 12.41$ & 2.191 & $0.030^{*}$ \\
\hline BMI $\left(\mathrm{kg} / \mathrm{m}^{2}\right)$ & $27.19 \pm 4.48$ & $26.74 \pm 3.85$ & $27.58 \pm 4.97$ & -1.107 & 0.270 \\
\hline \multicolumn{6}{|l|}{ Clinical characteristics } \\
\hline $\mathrm{SBP}(\mathrm{mmHg})$ & $131.16 \pm 16.71$ & $132.83 \pm 19.47$ & $129.76 \pm 16.04$ & 1.081 & 0.281 \\
\hline $\mathrm{DBP}(\mathrm{mmHg})$ & $77.56 \pm 9.91$ & $78.47 \pm 9.73$ & $76.79 \pm 9.91$ & 0.998 & 0.320 \\
\hline FBS $\left(\mathrm{mmol}^{-1}\right)$ & $6.91 \pm 2.43$ & $6.79 \pm 2.29$ & $7.02 \pm 2.55$ & -0.538 & 0.591 \\
\hline \multicolumn{6}{|l|}{ Physical functioning } \\
\hline ADL & $18.00 \pm 22.32$ & $17.50 \pm 26.13$ & $18.42 \pm 18.69$ & 0.532 & 0.809 \\
\hline HGS (Kgf) & $23.11 \pm 6.61$ & $26.01 \pm 7.03$ & $20.66 \pm 5.11$ & 2.316 & $0.001^{* *}$ \\
\hline MWD (m) & $333.29 \pm 29$ & $363.91 \pm 129.93$ & $307.50 \pm 53.47$ & -1.749 & $0.001^{* *}$ \\
\hline $\mathrm{VO}_{2} \max (\mathrm{mL} / \mathrm{kg} / \mathrm{min})$ & $9.05 \pm 1.65$ & $9.57 \pm 2.13$ & $8.63 \pm 0.89$ & 2.175 & $0.001^{* *}$ \\
\hline \multicolumn{6}{|l|}{ Psychosocial factor } \\
\hline DpS & $6.24 \pm 4.34$ & $5.93 \pm 4.23$ & $6.49 \pm 4.44$ & 1.446 & 0.457 \\
\hline ESE & $45.56 \pm 20.76$ & $50.40 \pm 24.01$ & $44.52 \pm 22.98$ & -1.106 & 0.079 \\
\hline PEB & $90.39 \pm 10.62$ & $91.59 \pm 10.04$ & $89.37 \pm 11.05$ & 2.520 & 0.218 \\
\hline
\end{tabular}

${ }^{*} \mathrm{P}<0.05 ;{ }^{* *} \mathrm{P}<0.001 ;$

Key: SD: Standard deviation; BMI: Body Max Index; HR: Heart rate; SBP: Systolic blood pressure; DBP: Diastolic blood pressure; FBS: Fasting blood sugar; ADL: Activity of daily living; HGS: Hand grip strength; 6MWD: Six minute walk distance; $\mathrm{VO}_{2}$ max: Maximal oxygen consumption; DpS: Depressed symptoms; ESE: Exercise self-efficacy; PEB: Perceived exercise benefit.

exercise. The procedure for assessing ESE was described in our previous study [25].

Perceived exercise benefit (PEB): The Exercise Benefit and Barrier Scale (EBBS) was used in this study. It consists of a 42-item Likert scale with four alternative answers. The score "four" corresponds to strong agreement with the assertion, "three" to simple agreement, "two" to simple disagreement and "one" to strong disagreement with the item. The scale includes two subscales: 29 items for the subscale of perceived exercise benefits and 14 for the subscale of perceived exercise barriers while perceived exercise benefits comprised of 28 items. In the subscales, a higher score corresponds to a higher perception concerning exercise benefit [26]. Perceived exercise benefits scale could be used separately as described by the authors [26]. The procedure was described in our previous study.

\section{Data Analysis}

Descriptive statistics of frequency, percentage, percentile, mean and standard deviation were used to summarize data. Independent t-test was used to determine the difference in physical and clinical characteristics, physical functioning and psychosocial factors between male and female participants. The association between physical functioning, psychosocial factors and socio-demographic characteristics of participants were explored using logistic regression analysis with odd ratio (OR) at 95\% confidence interval (Cl). Statistical Package of Social Science (SPSS) version 20 IBM (SPSS Inc.) was used for the data analysis. Alpha level was set at $p<0.05$.

\section{Results}

Table 1 shows socio-demographic characteristics of participants. More than half, 76 (54.30\%) were females and a majority, 123 (87.90\%) were married. The distribution of psychosocial factors of the participants shows that a fifth, $21(15.00 \%)$ of the participants were presented with depressive symptom while more than a quarter, $40(28.57 \%)$ of the participants reported high perceived exercise self-efficacy. Table 2 shows the comparison of physical, clinical characteristics, physical functioning and psychosocial factors between male and female participants. The mean age of all participants was $61.53 \pm 12.23$ years. All participants were comparable in both physical and clinical characteristics $(P>0.05)$ except in height and weight $(P<0.05)$. There were significant differences in physical functioning between males and females in HGS ( $26.01 \pm 7.03$ vs. $20.66 \pm 5.11 \mathrm{Kgf} ; t=2.316 ; P=0.001$ ), FC: 6-MWD (363.91 \pm 129.93 vs. $307.50 \pm 53.47 \mathrm{~m} ; \mathrm{t}=$ $-1.749, \mathrm{P}=0.001)$ and $\mathrm{VO}_{2} \max (9.57 \pm 2.13$ vs. $8.63 \pm$ $0.89 \mathrm{~mL} / \mathrm{kg} / \mathrm{min} ; \mathrm{t}=2.175 ; \mathrm{P}=0.001)$ but not in $\mathrm{ADL}(\mathrm{P}=$ 0.809). Furthermore, there was no significant difference in all psychosocial factors between male and female participants $(P>0.05)$. Table 3 shows logistic regression 
Table 3: Associations between depressive status and socio-demographic characteristics of participants $(N=140)$.

\begin{tabular}{|c|c|c|c|c|c|c|}
\hline \multicolumn{7}{|c|}{ Depressive Status } \\
\hline \multirow[b]{2}{*}{ Variable } & \multicolumn{3}{|c|}{ Non-depressed $(n=119)$} & \multicolumn{3}{|c|}{ Depressed $(n=21)$} \\
\hline & OR & $95 \% \mathrm{Cl}$ & P-value & OR & $95 \% \mathrm{Cl}$ & P-value \\
\hline \multicolumn{7}{|l|}{ Sex } \\
\hline Male & 1.00 & 1 (Ref) & & 1.00 & 1 (Ref) & \\
\hline Female & 1.07 & $0.32-3.12$ & 0.990 & 0.99 & $0.31-3.09$ & 0.992 \\
\hline \multicolumn{7}{|l|}{ Marital status } \\
\hline Single & 1.00 & 1 (Ref) & & 1.00 & 1 (Ref) & \\
\hline Married & 0.53 & $0.11-2.49$ & 0.405 & 1.87 & $0.40-8.76$ & $0.027^{*}$ \\
\hline Widow & 0.45 & $0.23-1.78$ & 0.325 & 1.65 & $0.54-6.33$ & $0.034^{*}$ \\
\hline \multicolumn{7}{|l|}{ Occupation } \\
\hline Farming & 1.00 & 1 (Ref) & & 1.00 & 1 (Ref) & \\
\hline Civil servant & 0.23 & $0.01-5.57$ & 0.367 & 4.32 & $0.18-10.41$ & 0.367 \\
\hline Trader/Artisan & 1.32 & $0.11-15.40$ & 0.824 & 0.75 & $0.06-8.82$ & 0.824 \\
\hline Retiree & 1.03 & $0.08-12.89$ & 0.979 & 0.97 & $0.77-12.05$ & 0.979 \\
\hline Schooling & 1.39 & $0.33-6.72$ & 0.752 & 0.78 & $0.54-9.61$ & 0.773 \\
\hline \multicolumn{7}{|l|}{ Educational } \\
\hline Primary & 1.00 & 1 (Ref) & & 1.00 & 1 (Ref) & \\
\hline Secondary & 1.49 & $0.38-7.21$ & 0.619 & 0.67 & $0.13-3.24$ & 0.619 \\
\hline Post-Secondary & 0.68 & $0.27-10.27$ & 0.570 & 0.59 & $0.97-3.61$ & 0.570 \\
\hline
\end{tabular}

"P $<0.05$

Key: OR: Odd Ratio; Cl: Confidence Interval; Ref: Reference.

Table 4: Associations between physical functioning and psychosocial factors $(N=140)$.

\begin{tabular}{|c|c|c|c|c|c|c|c|c|c|}
\hline \multicolumn{10}{|c|}{ Physical Functioning } \\
\hline & \multicolumn{3}{|c|}{ Activity of daily living } & \multicolumn{3}{|c|}{ Handgrip strength } & \multicolumn{3}{|c|}{ Functional capacity } \\
\hline Variable & OR & $95 \% \mathrm{Cl}$ & P-value & OR & $95 \% \mathrm{Cl}$ & P-value & OR & $95 \% \mathrm{Cl}$ & P-value \\
\hline \multicolumn{10}{|c|}{ Depressive status } \\
\hline Non-depressed & 1.00 & \multicolumn{2}{|l|}{ (Ref) } & 1.00 & \multicolumn{2}{|l|}{ (Ref) } & 1.00 & \multicolumn{2}{|l|}{ (Ref) } \\
\hline Depressed & 0.94 & $0.33-2.68$ & 0.124 & 1.30 & $0.74-2.28$ & 0.382 & 0.58 & $0.15-2.17$ & 0.462 \\
\hline \multicolumn{10}{|c|}{ Exercise self-efficacy } \\
\hline Low & 1.00 & \multicolumn{2}{|l|}{ (Ref) } & 1.00 & \multicolumn{2}{|l|}{ (Ref) } & 1.00 & \multicolumn{2}{|l|}{ (Ref) } \\
\hline High & 2.20 & $1.12-4.14$ & $0.026^{*}$ & 2.85 & 2.58-3.12 & $0.012^{*}$ & 2.96 & $1.91-4.58$ & $0.003^{*}$ \\
\hline \multicolumn{10}{|c|}{ Perceived exercise benefit } \\
\hline Low & 1.00 & \multicolumn{2}{|l|}{ (Ref) } & 1.00 & \multicolumn{2}{|l|}{ (Ref) } & 1.00 & \multicolumn{2}{|l|}{ (Ref) } \\
\hline High & 2.41 & $1.27-4.57$ & $0.017^{*}$ & 1.84 & $1.09-3.12$ & $0.039^{*}$ & 3.34 & $1.08-10.27$ & $0.034^{*}$ \\
\hline
\end{tabular}

${ }^{*} \mathrm{P}<0.05$

Key: OR: Odd ratio; Cl: Confidence interval; Ref: Reference.

analysis of association between depressive status and socio-demographic characteristics. Among those without depressive symptoms, the results show that there was no significant association between non-depression and each of sex, marital status, occupation and educational level $(P>0.05)$. However, among those that exhibited depressive symptoms, the result shows that married and widowed participants were almost twice likely to suffer depression $(\mathrm{OR}=1.87 ; 95 \% \mathrm{Cl}=0.40-8.76 ; \mathrm{P}=$ $0.027)$ and $(\mathrm{OR}=1.65,95 \% \mathrm{Cl}=0.54-6.33 ; \mathrm{P}=0.038)$, respectively.

Table 4 shows logistic regression analysis of association between physical functioning and psychosocial factors. There was no significant association between selected physical functioning and depression $(P>0.05)$. However, $A D L$ was more than twice likely associated with high ESE $(\mathrm{OR}=2.20 ; 95 \% \mathrm{Cl}=1.12-4.14 ; \mathrm{P}=0.026)$. Similarly, HGS and FC were almost thrice likely associated with high ESE $(\mathrm{OR}=2.85 ; 95 \% \mathrm{Cl}=2.58-3.12 ; \mathrm{P}=$ $0.012)$ and $(\mathrm{OR}=2.96 ; 95 \% \mathrm{Cl}=1.91-4.58 ; \mathrm{P}=0.003)$, respectively. Additionally, $\mathrm{ADL}(\mathrm{OR}=2.41 ; 95 \% \mathrm{Cl}=1.27$ 4.57; $\mathrm{P}=0.017), \mathrm{HGS}(\mathrm{OR}=1.84 ; 95 \% \mathrm{Cl}=1.09-3.12 ; \mathrm{P}=$ 
$0.039)$ and $\mathrm{FC}(\mathrm{OR}=3.34 ; 95 \% \mathrm{Cl}=1.08-10.27 ; \mathrm{P}=0.034)$ were significantly associated with high PEB.

\section{Discussion}

This study investigated the associations between physical functioning and psychosocial factors among patients with Type-2 Diabetes Mellitus (T2DM). Findings from this study show that about $15 \%$ of the study population presented with depressive symptoms. This finding is in line with previous studies that presence of T2DM is likely to result into depression $[27,28]$. Similarly, Anderson, et al. [10] and Cherrington, et al. [29] reported incidence of depression in patients with T2DM. It is possible that the impact of the disease on the metabolic system with high blood sugar, sudden dietary restriction, easy fatigability and sudden changes in social life may impact negatively on psychological wellbeing of patients with T2DM $[29,30]$. Other factors such as marital status; being married or widowed may also be responsible for depression as it was found in this study that such individuals were almost twice like to suffer depression. More importantly, some previous studies have implicated gender in the incidence of depression in people with T2DM $[10,29]$. Further studies are needed to ascertain the role of gender in depression. In the present study, the prevalence of depression appears to be moderately high. Although several factors may be responsible, the impact of the disease on musculoskeletal, neurological and cardiovascular systems may also contribute to high incidence of depression in people with T2DM. In the present study, it was observed that many of these patients were on regular anti-diabetic medications and lifestyle programmes with effective control of blood sugar level, these treatments were expected to offer a sense of psychological well-being among the patients with T2DM and low level of depression. There is the need to look at other possible causes of depression in T2DM.

Findings from this study showed that the handgrip strength of participants was poor. This finding is similar to that of previous studies reporting poor HGS [31,32]. A previous study by Wander, et al. [33] reported that the important predictor of survival in a diabetic population is good muscular strength having described handgrip strength as a measure of total body strength which is significantly associated with good physical performance. Similarly, the functional capacity in this study was low compared with healthy individuals. This is in line with the findings of previous studies that patients with T2DM have impaired functional capacity [20,34]. This implies that patients with T2DM have impaired oxygen utilization as regards physical performance. The plausible explanation for the low functional capacity might be as a result of negative effect of hyperglycemia on muscular strength, endurance and poor glucose metabolism.

Psychosocial factors are strong determinants of health outcomes in the rehabilitation of chronic dis- eases especially T2DM. In this present study, more than a quarter of participants reported moderate to high exercise self-efficacy. The associations between physical functioning and psychosocial factors were also explored. All physical functioning fields; activity of daily living, handgrip strength and functional capacity were significantly associated with high exercise self-efficacy. Exercise self-efficacy is the ability to engage in exercise programme with unmitigated confidence to commence and push through to the end. This finding is in agreement with previous a study that exercise self-efficacy among patients with T2DM helps patients to maintain regular exercise practice and subsequently improve self-care [35]. Exercise as a health behaviour plays significant role in the management of glycemic control and improvement in physical functioning [36]. This implies that exercise self-efficacy is considered to be an important factor for implementing rehabilitation goals and effective self-care management for patients with T2DM.

The ability to identify the importance of exercise benefit may play significant role in overcoming most barriers that could limit exercise participation among patients with chronic diseases. Perceived exercise benefit is the ability to be aware of role of exercise for improving health. In the present study, it was observed that all physical functioning areas were significantly associated with high perceived exercise benefit. However, this finding is in contrast to a previous study that patients with T2DM usually present with difficulty in engaging regular exercise programmes [37]. The possible explanation for this may not be unconnected with low level of awareness of the benefit of exercise to improve physical functioning and control of plasma blood sugar. Physical activity as exercise behaviour has both physiologic and psychological components of bio-psychosocial model that is necessary for achieving effective rehabilitation goal in T2DM. It is now evident that increased physical activity and resistance training are independently associated with physical functioning and psychological well-being of patients with T2DM [38].

\section{Limitations}

The results of this study should be interpreted with cautions due to some limitations therein. The study design is a cross-sectional one and causal relationship could not be established. Similarly, the sample size was based on a sample size formula using the prevalence of T2DM in Nigeria and this may not be true representative of people with T2DM. Nonetheless, participants were carefully recruited into the study in the same hospitals setting with the view to recruiting a homogeneous group. Furthermore, although time since diagnosis of T2DM varied among the participants, clinical and laboratory assessment of T2DM provided an evidence of T2DM for inclusion criteria into the study. In addition, psychosocial factors addressed in this study were assessed through validated questionnaires; sometimes 
measurements of these factors could be exaggerated or underestimated.

\section{Conclusions}

In conclusion, patients with T2DM exhibited reduced PhF in terms of ADL, HGS and 6-MWD but demonstrated moderate to high ESE and PEB. However, a sizable number of patients with T2DM presented with some level of depression. Furthermore, PhF was significantly associated with high ESE and PEB. These findings have implications on the importance of addressing psychosocial issues during rehabilitation programme. Regular assessment of psychosocial factors is recommended as part of routine procedures for effective rehabilitation of persons with T2DM. Hence, improved PhF and better PsF could enhance rehabilitation outcomes in people with T2DM.

\section{Acknowledgements}

The authors wish to thank the Consortium for Advanced Research Training in Africa (CARTA) for providing technical support. CARTA is jointly led by the African Population and Health Research Center and the University of the Witwatersrand, and funded by the Wellcome Trust (UK) (Grant No: 087547/Z/08/Z), the Department for International Development (DFID) under the Development Partnerships in Higher Education (DelPHE) and the Carnegie Corporation of New York (Grant No: B 8606), the Ford Foundation (Grant No: 1100-0399). Other partners include Swedish International Development Corporation Agency - SIDA (grant: 54100029), Google. Org (Grant No: 191994), and MacArthur Foundation Grant No: 10-95915-000-INP. We also wish to thank all participants for their cooperation.

\section{Conflict of Interest}

The authors declared none.

\section{Sources of Support}

No funding was received from any organization.

\section{Statement of Equal Authors' Contribution}

All the authors contributed to the research work up to this level.

\section{References}

1. International Diabetes Federation (2017) IDF Diabetes Atlas. ( $8^{\text {th }}$ edn), Brussels, Belgium.

2. Harding JL, Pavkov ME, Magliano DJ, Shaw JE, Gregg EW (2019) Global trends in diabetes complications: A review of current evidence. Diabetologia 62: 3-16.

3. International Diabetes Federation (2011) IDF Diabetes Atlas. ( $5^{\text {th }}$ edn), Brussels, Belgium.

4. Awotidebe TO, Adedoyin RA, Afolabi MA, Opiyo R (2016) Knowledge, attitude and practice of exercise for plasma blood glucose control among patients with type-2 diabetes. Diabetes Metab Syndr 2016: S1-S6.

5. International Diabetes Federation (2013) IDF Diabetes Atlas. (6 $6^{\text {th }}$ edn), Brussels, Belgium.
6. Ogbera AO, Ekpebegh C (2014) Diabetes mellitus in Nigeria: The past, present and future. WJD 5: 905-911.

7. American Diabetes Association (2014) Standards of medical care in Diabetes. Diabetes Care 37: S14-S80.

8. Cioroiu CM, Brannagan TH (2014) Peripheral neuropathy. Curr Geriatr Reports 3: 83-90.

9. Dessie $G$, Mulugeta $H$, Amare $D$, Negesse $A$, Wagnew $F$, et al. (2020) A systematic analysis on prevalence and sub-regional distribution of undiagnosed diabetes mellitus among adults in African countries. J Diabetes Metab Disord 19: 1931-1941.

10. Chima CC, Salemi JL, Wang M, Mejia de Grubb MC, Gonzalez SJ, et al. (2017) Multimorbidity is associated with increased rates of depression in patients hospitalized with diabetes mellitus in the United States. J Diabetes Complications 31: 1571-1579.

11. Umpierre D, Ribeiro PA, Kramer CK, Leitão CB, Zucatti AT, et al. (2011) Physical activity advice only or structured exercise training and association with $\mathrm{HbA} 1 \mathrm{c}$ levels in type 2 diabetes: A systematic review and meta-analysis. JAMA 305: 1790-1799.

12. Shrestha M, Ng A, Al-Ghareeb A, Alenazi F, Gray R (2020) Association between sub threshold depression and self-care behaviors in people with type 2 diabetes: A systematic review of observational studies. Syst Rev 9: 45.

13. Song J, Koh TH, Park O, Kwon D, Kang S, et al. (2019) Association between depression and cardiovascular disease risk in general population of Korea: Results from the Korea National Health and Nutrition Examination Survey, 2016. Ann Occup Environ Med 31: e10.

14. Boger E, Ellis J, Latter S, Foster C, Kennedy A, et al. (2015) Self-Management and self-management support outcomes: A systematic review and mixed research synthesis of stakeholder views. PLoS One 10: e0130990.

15. Bandura A (1997) Self-efficacy: The exercise of control. Freeman, New York, USA.

16. Kasiulevičius V, Šapoka V, Filipavičiūtè R (2006) Sample size calculation in epidemiological studies. Gerontologija 7: 225-231.

17. Pincus $T$, Sokka T, Kautiainen $H$ (2005) Further development of a physical function scale on a multidimensional health assessment questionnaire for standard care of patients with rheumatic diseases. J Rheumatol 32: 1432-1439.

18. Awotidebe TO, Adedoyin RA, Balogun MO, Adebayo RA, Adeyeye VO, et al. (2016) Effects of cardiac rehabilitation exercise protocols on physical function in patients with chronic heart failure. Int J Clin Med 7: 547-557.

19. American Society of Hand Therapists (2015) Clinical Assessment Recommendation. ( $3^{\text {rd }}$ edn), American Society of Hand Therapist.

20. Awotidebe TO, Adedoyin RA, Yusuf AO, Mbada CE, Opiyo $R$, et al. (2014) Comparative functional exercise capacity of patients with type - 2 diabetes and healthy controls: A case-control study. Pan Afr Med J 19: 257.

21. American Thoracic Society (2002) Guidelines for six-minute walk test. Am J Respir Crit Care Med 166: 111-117.

22. Awotidebe TO, Adeyeye VO, Adedoyin RA, Oke IK, Ativie $\mathrm{RN}$, et al. (2016) Assessment of functional capacity in Nigerian patients with hypertension using the six-minute walk test. West Indian Med J.

23. Radloff $L$ (1977) The CES-D scale: A self-report depression 
scale for research in the general population. App Psych Measure 3: 385-401.

24. Bjorgvinsson T, Kertz SJ, Bigda-Peyton JS, McCoy KL, Aderka IM (2013) Psychometric properties of the CES-D-10 in a psychiatric sample. Assessment 20: 429-436.

25. Awotidebe TO, Ativie RN, Oke KI, Adedoyin RA, Nabakwe EC, et al. (2017) Prevalence of physical inactivity among Nigerian women: Do socio-demographic, women's personal attributes and psychosocial factors play any role? J Exerc Ther 4: 33-45.

26. Sechrist KR, Walker SN, Pender NJ (1987) Development and psychometric evaluation of the exercise benefits/barriers scale. Res Nurs Health 10: 357-365.

27. Mezuk B, Eaton WW, Albrecht S, Golden SH (2008) Depression and type 2 diabetes over the lifespan: A meta-analysis. Diabetes Care 31: 2383-2390.

28. Musselman DL, Ziemer DC, McNutt MD, Seay JS, Royster EB, et al. (2014) Depression, deficits in functional capacity and impaired glycemic control in urban African Americans with type 2 diabetes. J Psychiatr Res 52: 21-27.

29. Cherrington A, Wallston KA, Rothman RL (2010) Exploring the relationship between diabetes self-efficacy, depressive symptoms, and glycemic control among men and women with type 2 diabetes. J Behav Med 33: 81-89.

30. Awotidebe TO, Adedoyin RA, Oke IK, Ativie RN, Opiyo R, et al. (2017) Relationship between functional capacity and health-related quality of life of patients with type-2 diabetes. Diabetes Metab Syndr 11: 1-5.
31. Gundmi S, Maiya AG, Bhat AK, Ravishankar N, Hande MH, et al. (2018) Hand dysfunction in type 2 diabetes mellitus: Systematic review with meta-analysis. Ann Phys Rehabil Med 61: 99-104.

32. Li K, Wei N, Cheng M, Hou X, Song J (2018) Dynamical coordination of hand intrinsic muscles for precision grip in diabetes mellitus. Sci Rep 8: 4365.

33. Wander PL, Boyko EJ, Kahn SE (2011) Greater hand grip strength predicts a lower risk of developing type 2 diabetes over 10 years in leaner Japanese Americans. Diabetes Res Clin Pract 92: 261-264.

34. Santos JJA, Brofman PRS (2008) Six-minute walk test and quality-of-life in heart failure: A correlative study with a Brazilian sample. Insuficiencia Cardiaca 3: 72-75.

35. Reisi M, Mostafavi F, Javadzade $H$, Mahaki B, Tavassoli E, et al. (2016) Impact of health literacy, self-efficacy, and outcome expectations on adherence to self-care behaviors in Iranians with Type - 2 Diabetes. Oman Med J 31: 52-59.

36. Schwaab B, Windmöller M, König IR, Schütt M (2020) Evaluation of aerobic exercise intensity in patients with coronary artery disease and type 2 diabetes mellitus. $J$ Clin Med 9: 2773.

37. Baptista LC, Dias G, Souza NR, Veríssimo MT, Martins RA (2017) Effects of long-term multicomponent exercise on health-related quality of life in older adults with type 2 diabetes: Evidence from a cohort study. Qual Life Res 26: 2117-2127.

38. Memelink RG, Pasman WJ, Bongers A, Tump A, van Ginkel A, et al. (2020) Effect of an enriched protein drink on muscle mass and glycemic control during combined lifestyle intervention in older adults with obesity and type 2 diabetes: a double-blind RCT. Nutrients 13: 64. 